\title{
Esponjas de água doce na América do Sul: 0 estado da arte da produção científica no Brasil
}

\section{Freshwater sponges in South America: the state of the art of SCientific production in Brazil}

\author{
Elaine Cristina Zavadovski Kalinovski ${ }^{1}$, Mauro Parolin², Edvard Elias de Souza Filho ${ }^{3}$ \\ 1- Progr. Pós-Grad. Geografia, Univ. Est. Maringá, UEM, \\ Av. Colombo, 5790, Maringá, PR, elaine kalinovski@hotmail.com \\ 2 - Lab. Est. Paleoamb. Fecilcam, Univ. Est. Paraná, Unespar, Av. Com. Norberto Marcondes, 773, Campo Mourão, PR. \\ 3 - Univ. Est. Maringá, UEM, Av. Colombo, Maringá, PR
}

ABSTRACT: This work presents an updated review of scientific studies involving the fauna of freshwater sponges in South America, especially of studies conducted in Brazil. A study was conducted of the scientific production regarding the occurrence and distribution of freshwater sponges, and of the use of their siliceous spicules, preserved in sedimentary deposits, as proxy for paleoenvironmental reconstruction studies. The studies are relatively more developed in the South-Central and North of the country. However, it is evident that there is a need for more comprehensive and intensive studies of the description of current species and their identification in sedimentary sequences.

\section{Manuscrito:}

Recebido: 27/04/2015

Corrigido: $30 / 10 / 2015$

Aceito: $30 / 11 / 2015$

Citation: Kalinovski E.C.Z., Parolin M., Souza Filho E.E. 2016. Esponjas de água doce na América do Sul: 0 estado da arte da produção científica no Brasil. Terræ Didatica, 12(1):4-18. < http://www. ige.unicamp.br/terraedidatica/ $>$.

Keywords: Freshwater sponges, Siliceous spicules, paleoenvironmental reconstruction.

\section{Introdução}

As esponjas são animais exclusivamente aquáticos (marinhos e/ou dulciaquícolas) membros do filo Porifera. São metazoários, de vida bentônica séssil, que vivem aderidos a substratos rochosos ou mesmo sobre restos de vegetação submersa, incrustando raízes de macrófitas, galhos ou troncos de árvores em regiões que sofrem inundações sazonais, como nas várzeas dos grandes rios amazônicos (Volkmer-Ribeiro 1999, Volkmer-Ribeiro e Pauls 2000). Uma característica fundamental comum a todas as esponjas é sua função filtradora, atuando no meio aquático como verdadeiras bombas aspirante-prementes, uma vez que a água do ambiente é absorvida pelos poros, filtrada nas câmaras coanocitárias e expelida novamente para o meio aquático através dos ósculos, orifícios de saída de água (Volkmer-Ribeiro e Parolin 2010). O esqueleto das esponjas é constituído por espículas (silicosas ou carbonáticas) que ao entrelaçarem-se formam uma trama complexa que dá sustentação ao corpo principal e proporciona uma estrutura de sustentação para as células vivas do animal.
Este trabalho atualiza o estado da arte das principais pesquisas sobre o registro e ocorrência de esponjas de água doce na América do Sul, com destaque para o Brasil, assim como da sua utilização como dado proxy em estudos de reconstrução paleoambiental, através das espículas presentes em colunas de sedimentos, sendo observadas majoritariamente em depósitos lacustres do Quaternário.

Até a primeira metade do século XX, os levantamentos e descrições da fauna de esponjas continentais brasileiras eram escassos e incipientes, atingindo maior notoriedade e repercussão no meio científico a partir da década de 1960, incluindo as pesquisas operadas por um considerável número de especialistas dedicados ao estudo e compreensão dessas comunidades bênticas. Por sua vez, a produção científica relativa à utilização de espículas de esponjas continentais como indicadoras de condições paleoambientais, adquiriu maior regularidade na segunda metade do século XX, com a intensificação das investigações no início do século XXI, destacando-se as abordagens principalmente na região Centro-Sul e Norte do Brasil. 


\section{Poríferos continentais}

\section{Características gerais das esponjas de água doce}

Como outros grupos de animais aquáticos, cuja origem está nos oceanos (crustáceos, moluscos, peixes, etc.) e que ao longo das eras geológicas deram origem a vários grupos taxonômicos continentais ao invadirem as águas doces dos continentes, algumas esponjas marinhas também mostraram potencialidade para ocupar as águas doces dos ambientes continentais, dando origem a novas espécies, gêneros e famílias (Volkmer-Ribeiro e Parolin 2010). Nesse aspecto, os autores apontam que as esponjas de água doce se originaram de esponjas marinhas em épocas geológicas passadas, que em algum momento da história evolutiva migraram dos oceanos para as águas continentais. No entanto, ao que tudo indica, apenas as esponjas marinhas com espículas silicosas tiveram sucesso na adaptação aos ambientes de águas continentais, uma vez que todas as esponjas de água doce conhecidas atualmente possuem esqueleto composto por espículas silicosas, ou seja, de opala, ressaltando que essas espículas são elementos fundamentais para a determinação das categorias taxonômicas, permitindo a identificação em nível de espécie (Volkmer-Ribeiro e Parolin 2010).

Esses elementos endo-esqueletais silicosos incluem as seguintes categorias: Megascleras ou macroscleras - espículas que integram a rede esqueletal e geralmente são as maiores espículas presentes; Microscleras - espículas de tamanho reduzido, localizadas preferencialmente na pinacoderme, superfície externa da esponja; estas espículas são utilizadas na identificação taxonômica de gêneros e espécies; Gemoscleras - espículas que revestem as gêmulas das esponjas de água doce e que constituem o caráter morfológico mais importante na caracterização de famílias, gêneros e espécies (Volkmer-Ribeiro e Pauls 2000).

A distribuição e proliferação de esponjas de água doce são regidas por fatores sazonais, relacionados às flutuações do nível da água, temperatura, turbidez, iluminação e disponibilidade de nutrientes (Frost 1991). Relacionam-se com determinados tipos de habitats, ocorrendo em ambientes lóticos ou lênticos, permanentes ou temporários, além da colonização de reservatórios de hidroelétricas conforme demonstrado por Volkmer-Ribeiro e Hatanaka (1991), como no lago da Usina Hidrelétrica de Tucuruí (PA), na região amazônica, bem como no reservatório de Itaipu (PR) (Volkmer-Ribeiro et al. 2010).

Nossa pesquisa analisou a produção científica sobre esponjas de água doce na América do Sul, com enfoque para o Brasil, delineando os percalços e as perspectivas para o desenvolvimento dos estudos nesse campo do conhecimento.

\section{Materiais e métodos}

Considerando tratar-se de atualização bibliográfica, para o levantamento dos trabalhos de teses, dissertações, artigos em periódicos, artigos em eventos científicos e resumos expandidos foi utilizado o buscador de periódicos da CAPES (www.periodicos. capes.gov.br), Google Scholar ${ }^{\circledR}$ (www.scholar.google.com.br), o acesso ao currículo Lattes (www.lattes. cnpq.br) dos principais pesquisadores sobre o tema no Brasil e solicitação via e-mail aos mesmos para o envio dos trabalhos. Para a espacialização geográfica das pesquisas foi utilizado o software CorelDraw x7 ${ }^{\circledR}$.

\section{Estudos sobre esponjas na América do Sul e Brasil}

\section{A espongiofauna continental sul-americana: estado da arte das pesquisas}

Atualmente, a comunidade de poríferos bentônicos inclui 8.532 espécies válidas conhecidas em âmbito mundial (Van Soest et al. 2014). Deste total, estima-se que apenas 220 espécies estão distribuídas nos ecossistemas aquáticos continentais, exigindo novos estudos e intensificação dos levantamentos dessa fauna dulciaquícola para a ampliação e o conhecimento mais exato do número de espécies que ocorrem no planeta.

Em termos de biodiversidade, é importante destacar que a América do Sul abriga uma das maiores diversidades mundiais de esponjas de água doce, em sua maioria, detectadas para as bacias dos rios Amazonas, Paraná e Uruguai, principalmente nos seus cursos médio e inferior. Todavia, ainda existem muitas áreas geográficas inexploradas, que requerem maior trato das questões pertinentes à totalidade da fauna de esponjas presentes, como é o caso das bacias dos rios sul-americanos da vertente do Pacífico e parte do Caribe (Volkmer-Ribeiro e Pauls 2000). Na América do Sul, o Brasil é o país que apresenta a maior diversidade de espécies conhecidas até o momento, seguido da Argentina e Venezuela 
(Ezcurra de Drago 1977, Volkmer-Ribeiro 1981).

O catálogo de poríferos brasileiros, produzido por Muricy et al. (2011) reúne uma compilação de todas as espécies já reportadas para o país e a bibliografia referente ao tema até o ano de 2010, incluindo 486 referências devidamente listadas e averiguadas. Neste catálogo, o Brasil mostra 53 espécies válidas de esponjas de água doce, distribuídas nas famílias Spongillidae (com 28 espécies identificadas) além de Potamolepidae e Metaniidae.

Volkmer-Ribeiro (2007) apresenta o estado da arte das pesquisas sobre as esponjas continentais na América do Sul, salientando que as primeiras descrições foram produzidas no século XIX, a partir de espécimes obtidos dos rios Orinoco, Amazonas e Uruguai. Estudos taxonômicos mais aprofundados foram desenvolvidos em meados do século $\mathrm{XX}$, ressaltando as pesquisas pioneiras efetuadas por Argentino A. Bonetto e Inês D. Ezcurra de Drago, que divulgaram trabalhos envolvendo a descrição e ocorrência de esponjas continentais para a região Neotropical, atentando-se para o exame das comunidades de poríferos argentinos.

Em 1966, os autores publicaram o registro de um novo gênero de esponja, Houssayella, tendo por base a identificação da espécie Houssayella iguazuensis, observada no Salto "San Martin", nas cataratas do Iguaçu, província de Misiones, na Argentina. No trabalho também realizaram a primeira descrição das espécies Corvospongilla seckti e Corvomeyenia australis, respectivamente, na localidade de Paso de la Patria, província de Corrientes (nas proximidades da confluência do alto Paraná com o rio Paraguai) e laguna Guadalupe, na província de Santa Fé.

Posteriormente, em trabalhos contíguos, Bonetto e Ezcurra de Drago (1969) apresentaram relevantes notas sistemáticas sobre o gênero Uruguaya Carter, 1881, propondo a criação de um novo gênero, denominado de Uruguayella, incluindo cinco espécies, todas sul-americanas e anteriormente descritas como do gênero Uruguaya, quais sejam: Uruguayella repens, com ocorrência no rio Uruguai e afluentes da porção superior do rio Paraná; U. macandrewi, no rio Paraguai e nos cursos superior, médio e inferior do rio Paraná; U. pygmaea, do rio Paraguai e Uruguai; $U$. amazonica, do rio Amazonas e U. ringueleti, do alto Paraná e rio Uruguai. No mesmo ano, Ezcurra de Drago e Bonetto (1969) caracterizaram a fauna bentônica dos saltos do rio Uruguai, em seu médio curso, com especial referência à ecologia dos poríferos.

Merece destaque a contribuição substancial dos estudos desenvolvidos pelos mesmos autores no ano de 1970, uma vez que ampliaram o registro de esponjas conhecidas para as águas continentais argentinas. Em suas pesquisas, listaram quinze espécies provenientes dos afluentes do alto rio Paraná, na província de Misiones, Argentina, com descrição de três novas espécies: Radiospongilla ornata, Trochospongilla tenuissima e Spongilla (Stratospongilla) atrata. Evidenciaram ainda a presença de duas outras espécies originárias do rio Uruguai e até então não identificadas para a área: Drulia uruguayensis Bonetto e Ezcurra de Drago, 1968 e Spongilla (Stratospongilla) ponsi Bonetto e Ezcurra de Drago, 1968.

Anos mais tarde, Ezcurra de Drago (1979) identificou um novo gênero sul-americano de esponjas de águas continentais, analisando materiais de Corvomeyenia australis Bonetto e Ezcurra de Drago, 1966 e de C. heterosclera Ezcurra de Drago, 1974. Constatou-se diferenças marcantes entre estas espécies registradas para a América do Sul em comparação com as descrições já disponíveis para as outras espécies do gênero, como C. everetti Mills, 1884 e C. carolinensis Harrison, 1971, ambas com distribuição na América Setentrional. Dessa maneira, baseando-se no critério estabelecido por Penney e Racek (1968) no que se refere aos elementos diagnósticos considerados para a diferenciação de gêneros, a autora definiu para as espécies sul-americanas o gênero Corvoheteromeyenia.

A maior coleção de esponjas de água doce detectadas na Argentina encontra-se depositada no Instituto Nacional de Limnologia - INALI, em Santa Fé, sendo, portanto, resultado de uma profunda e exaustiva atividade científica empreendida, principalmente, por Argentino Aurelio Bonetto e Inês Ezcurra de Drago. Os autores iniciaram e impulsionaram as pesquisas sobre essa fauna aquática no país, propondo a descrição de novas espécies e gêneros com base na análise de seus componentes espiculares, bem como a redescrição de eventuais grupos taxonômicos, contribuindo sobremaneira para estudos mais detalhados no tocante a riqueza de esponjas na América do Sul.

Não obstante, convém igualmente salientar a literatura especializada sobre poríferos no Brasil, onde os primeiros registros datam da segunda metade do século XIX, sobre espécimes coletados principalmente na Amazônia por naturalistas e viajantes europeus. Os materiais foram identificados por especialistas da época e depositados no Museu de História Natural de Londres (Inglaterra) e no Museu de Zoologia de Berlim (Alemanha), totalizando um registro de 17 espécies, das quais 13 constituem ainda espécies válidas (Volkmer-Ribeiro 1999). 
Em 1863, em sua monografia de esponjas de água doce, James Scott Bowerbank descreveu sete espécies para o Brasil, todas com ocorrência na região amazônica: Metania reticulata, Uruguaya corallioides, Trochospongilla gregaria, Trochospongilla paulula, Acalle recurvata, Drulia brownii e Spongilla baileyi. Ao fazer a revisão da literatura sobre poríferos brasileiros, Muricy et al. (2011) certificam que de 1890 à 1960 relativamente poucos estudos foram publicados. Em 1895, Weltner também apresentou o registro de esponjas de água doce para os bentos de um rio amazônico, ao descrever Uruguaya amazonica para o rio Amazonas.

Por sua vez, Lutz e Machado (1915) registraram Drulia brownii Bowerbank, 1863 como Spongilla franciscana para o rio São Francisco. Na sequência, Carvalho (1942) identificou Radiospongilla amazonensis Volkmer-Ribeiro e Maciel, 1983 como Ephydatia crateriformis para o rio Ribeira de Iguape, no litoral de São Paulo, sendo o primeiro registro da espécie para o Brasil. Em 1947, Machado iniciou os levantamentos de esponjas na bacia Araguaia/Tocantins, com a detecção de Tubella meloleitaoi para um contribuinte da margem esquerda do rio Araguaia (rio Tapirapés). Anos depois a espécie foi posta em sinonímia, parte em Metania reticulata Bowerbank, 1863 e parte em Trochospongilla pennsylvanica Potts, 1882, por Volkmer-Ribeiro (1984).

A partir da década de 1960 houve o incremento dos estudos e numerosos trabalhos foram publicados. Destacam-se as pesquisas realizadas por Cecília Volkmer-Ribeiro e demais pesquisadores colaboradores, que através de uma vasta e fecunda atividade científica, ampliaram a coleção de esponjas coligidas no Brasil. Neste período, nota-se a contribuição referente aos estudos taxonômicos, com a revisão e criação de gêneros, inventários e descrições de novas espécies, bem como a proposta de uma nova família (Metaniidae Volkmer-Ribeiro, 1986), tendo como ponto de partida, o estudo abrangente das esponjas de água doce produtoras de gêmulas, de Penney e Racek em 1968 (Volkmer-Ribeiro 1999).

No Brasil foram executados estudos abrangentes, principalmente na região amazônica e no Rio Grande do Sul. Em 1963, nos primórdios de seus estudos sobre a comunidade de esponjas brasileiras, Volkmer-Ribeiro efetuou o registro de esponja incrustando rochas de fundo de rios, com a descrição de Spongilla jewelli para o rio Tainhas, bacia do Taquari-Antas, no Rio Grande do Sul. Desde então, a produção científica voltada ao estudo da fauna espongiológica alcançou notável crescimento, de modo que, entre 1963 e 2010 a autora aludida publicou mais de 130 trabalhos, incluindo artigos, capítulos de livros e anais de congressos que se tornaram imprescindíveis para o conhecimento de esponjas, sobretudo de ambientes de água doce (Muricy et al. 2011).

Dessa forma, no desencadear de suas pesquisas, Volkmer-Ribeiro (1970) erigiu o gênero Oncosclera, tendo como espécie tipo Oncosclera jewelli, definida pela mesma autora como Spongilla jewelli no ano de 1963. Ainda na década de 1970, cabe mencionar o trabalho de Volkmer-Ribeiro \& De Rosa-Barbosa (1978) que elencaram um novo gênero de esponjas de água doce a partir de material coletado no rio Turvo, afluente do Paranaíba, na localidade de Paraúna, no Estado de Goiás e no rio Itararé, afluente do rio Paranapanema, na localidade de Carlópolis, no Estado do Paraná. As autoras realizaram a descrição da espécie Sterrastrolepis brasiliensis e diante da peculiaridade dos materiais estudados justificou-se a proposição do novo gênero Sterrastrolepis. No mesmo ano, Ezcurra de Drago (1978) descreveu e ilustrou Stratospongilla brasiliensis, que evidenciou as mesmas características espiculares de Sterrastrolepis brasiliensis Volkmer-Ribeiro \& De Rosa-Barbosa, 1978. Logo, as espécies então descritas podem ser interpretadas como sinônimo, tendo em vista que a análise baseou-se na mesma localidade e material tipo.

Posteriormente, Volkmer-Ribeiro \& De Rosa-Barbosa (1979), dando continuidade aos seus estudos do conjunto da bentobiota dulciaquícola da região Neotropical, posicionaram o novo gênero Sterrastrolepis na família Potamolepidae Brien, 1967, restrita até então à região Etiópica. Além desse, outros gêneros foram incluídos na família, entre eles Uruguaya Carter, 1881; Potamolepis Marshall, 1883; Potamophloios Brien, 1970; Stratospongilla Annandale, 1909 e Oncosclera Volkmer-Ribeiro, 1970.

Por sua vez, De Rosa-Barbosa (1979) redescreveu o material tipo de Ephydatia facunda, originalmente descrita por Weltner (1895) a partir de um único espécime coletado em uma pequena lagoa do Rio Grande do Sul. A autora salienta que a descrição original foi feita de maneira sucinta, incompleta e sem ilustrações, julgando necessário ampliar e ilustrar a descrição do holótipo de E. facunda, visando a manutenção do "status" de espécie.

Volkmer-Ribeiro e Maciel (1983), dedicando-se ao estudo de novas coleções de esponjas de água doce da região amazônica, apresentaram a primeira descrição de Spongilla spoliata e Radiospongilla amazonensis, com ilustração de seus componentes espiculares. No 
trabalho, os autores ainda fizeram o primeiro registro de ocorrência de Trochospongilla variabilis Bonetto e Ezcurra de Drago, 1973 e Trochospongilla pennsylvanica Potts, 1882 para a Amazônia brasileira, sendo essa última o primeiro registro para a região neotropical. Em 1984, Volkmer-Ribeiro propondo a revisão do gênero Metania Gray, 1867, realizou a redescrição de duas espécies neotropicais de águas amazônicas, isto é, Metania reticulata Bowerbank, 1863 e Metania spinata Carter, 1881.

De Rosa Barbosa (1988) descreveu Corvospongilla volkmeri procedente da Lagoa Dourada, Paraíba, bem como efetivou o primeiro registro de ocorrência de Corvospongilla seckti Bonetto e Ezcurra de Drago, 1966 para o Brasil, no Rio Grande do Sul, visto que a espécie era conhecida, até então, apenas na Argentina.

Da mesma forma, na década de 1990 foram divulgados novos estudos sobre sistemática e distribuição de esponjas de água doce no Brasil. Cita-se Volkmer-Ribeiro (1990), que dissertou a respeito da sistemática, evolução e taxonomia de esponjas continentais, com importantes considerações sobre o gênero Metania e sua extensão para a região neotropical. Tavares (1994), em sua dissertação de mestrado, abordou o estudo das comunidades bênticas de substratos rochosos de rios amazônicos, com redefinição e chave taxonômica das espécies do gênero Drulia Gray, 1867. No levantamento correspondente as esponjas de água doce do Estado de São Paulo, apenas seis espécies haviam sido registradas, com informações pertinentes a sua posição taxonômica e hábitos de ocorrência (Volkmer-Ribeiro 1999).

Um número significativo de trabalhos publicados por diferentes autores marca o início do século XXI, caracterizado por um crescimento exponencial da literatura sobre Porifera. Vários grupos foram redescritos em estudos recém-publicados, com notícias de novos registros de espécies, contribuindo, desse modo, para um conhecimento mais sólido da fauna sul-americana de esponjas com ocorrência em ecossistemas aquáticos continentais brasileiros. Para a região Centro-Oeste do Brasil, Batista e Volkmer-Ribeiro (2002) realizaram o levantamento das comunidades de esponjas do leito de rios à jusante das barragens da Usina Hidrelétrica de Corumbá (bacia do Paraná) no Estado de Goiás e da Usina Hidrelétrica do rio Manso (bacia do Paraguai) no Estado do Mato Grosso, com redescrição de Oncosclera schubarti Bonetto e Ezcurra de Drago, 1967.

Para a Amazônia Central, merece destaque o trabalho de Batista et al. (2003), que fizeram estudo de caráter ecológico, tendo as esponjas como indicadoras ambientais e listaram os registros até então feitos para a fauna espongiológica no curso inferior da bacia do rio Araguaia. Do mesmo modo, na região Sudeste, Pinheiro et al. (2003) ampliaram o registro de ocorrência de esponjas para águas continentais do Estado de São Paulo, fornecendo a redescrição de três espécies pela primeira vez registradas para a Bacia do Alto Paraná: Oncosclera navicella Carter, 1881; Uruguaya corallioides Bowerbank, 1863 e Corvospongilla seckti Bonetto e Ezcurra de Drago, 1966. Os espécimes coletados no Rio Tietê, no município de Itapura/SP, elevaram para nove o número de espécies conhecidas no Estado.

Em 2005, Volkmer-Ribeiro \& Parolin publicaram o segundo registro de Sterrastrolepis brasiliensis Volkmer-Ribeiro \& De Rosa-Barbosa, 1978 para a Bacia do Paraná. A espécie foi detectada no fundo rochoso do rio Piquiri, associada com Oncosclera navicella e Oncosclera tonolli, ressaltando que essa última teve seu primeiro registro para águas brasileiras e para a Bacia do Paraná, uma vez que a mesma foi descrita originalmente por Bonetto e Ezcurra de Drago (1968) somente para a bacia do rio Uruguai.

Extensas coleções feitas ao longo da costa brasileira resultaram em grande número de novas espécies e novos registros de esponjas. Destaca-se o trabalho de Volkmer-Ribeiro \& Machado (2007), que conduziram os levantamentos para a detecção de esponjas dulcícolas em diversos corpos d'água de ambientes costeiros na América do Sul, particularmente no Brasil, demonstrando que as espécies recorrentes são indicadoras de habitats. Ainda no ano de 2007 as investigações realizadas por Pinheiro, que em sua tese de doutoramento discutiu a taxonomia e biogeografia das esponjas de águas continentais, mostra que as áreas com menor número de registros de esponjas no Brasil são justamente os estados litorâneos da Região Nordeste. O autor indagou que um dos prováveis motivos para essa escassez de registros na região está atrelado à ausência de inventários espongiológicos e esforços amostrais, existindo lacunas a serem preenchidas para um conhecimento biogeográfico mais preciso.

Em relação à Região Sul, notícias sobre a existência de uma fauna de esponjas de água doce podem ser constatadas no Paraná, em estudo desenvolvido por Volkmer-Ribeiro e Parolin (2010). Os autores apresentaram uma listagem das espécies detectadas para o Estado, tanto por suas espículas presentes em sedimentos de paleoambientes, quanto pela ocorrência de esponjas vivas no lei- 
to de diversos rios (ambientes lóticos) ou ainda em substratos mergulhados em águas represadas (ambientes lênticos).

Com o propósito de levantamento da espongiofauna paranaense, foram abordadas no trabalho seis bacias hidrográficas, das quais apenas as bacias do Ivaí, Paraná 2, Paraná 3 e Piquiri revelaram resultados positivos, enquanto para as bacias da região litorânea, do Paraná 1, Ribeira e Tibagi não houve o registro de esponjas. Os autores alertam que as bacias que apontaram resultados negativos, requerem avaliações mais detalhadas e abrangentes, sendo bastante promissoras as possibilidades de detecção dessa fauna, especialmente para a bacia do Paraná 1 , visto que a maioria dos rios exibem águas com baixa carga suspensa, dispondo de segmentos caracterizados por corredeiras e pequenas quedas d'água, portanto ideais para a presença de esponjas.

A coleção de referência de esponjas de água doce do Brasil encontra-se no Museu de Ciências Naturais da Fundação Zoobotânica do Rio Grande do Sul, em Porto Alegre/RS, compondo um rico acervo das espécies até recentemente amostradas no país. Atualmente, essa fauna tem representação e abundância excepcionais na região amazônica e em certos ambientes formados por pequenas lagoas no cerrado (Volkmer-Ribeiro 1999). No Estado do Rio Grande do Sul, onde o levantamento foi iniciado em 1960, Volkmer-Ribeiro e Parolin (2010) informam que contabiliza até o presente momento o registro de 22 espécies dessa fauna brasileira, que ocupam rios, arroios, lagoas e banhados costeiros, lagos de hidrelétricas e açudes em propriedades rurais.

Todavia, Volkmer-Ribeiro (1999) adverte a necessidade de coletas mais abrangentes na região Neotropical, asseverando que os bentos profundos dos grandes rios do planeta não foram ainda meticulosamente prospectados, em virtude das dificuldades de realização de amostragens nesses ambientes. A possibilidade de amostrar extensivamente as comunidades de esponjas que se desenvolvem no leito profundo de grandes rios brasileiros surgiu, nas últimas décadas, por ocasião da intensificação da construção de barragens para a formação dos lagos de hidrelétricas. Nesses momentos, os leitos à jusante das barragens ficam expostos, permitindo coletas representativas e o estudo das assembleias de esponjas, porventura fixadas nesses locais (Volkmer-Ribeiro 1999, Batista e Volkmer-Ribeiro 2002).

Apesar das numerosas pesquisas feitas no Brasil, a taxonomia e distribuição da fauna de esponjas ainda não são suficientemente compreendidas. A esse respeito, Custódio \& Hajdu (2011) comentam que as esponjas são historicamente consideradas um grupo de taxonomia complexa, sendo comuns discussões em torno da sua sistemática. Disto decorre que muitos grupos ainda não possuem uma posição taxonômica precisamente definida, havendo problemas de sinonímia e com chaves de identificação, cenário que orienta para a necessidade de contínua e profunda revisão dos táxons julgados válidos, objetivando assim uma base taxonômica mais sólida. Adicionalmente, com relação à biogeografia desses organismos, existem muitas regiões e localidades que não foram tomadas como objeto de investigação da fauna espongiológica, e desse modo, carecem de avaliação e de inventário mais completo (Muricy et al. 2011).

Estudos menos expressivos sobre descrição, registro, taxonomia e distribuição de esponjas continentais na América do Sul também foram produzidos, de maneira pontual, no Chile (Ezcurra de Drago 1974, Kilian e Wintermann-Kilian 1976), Suriname (Ezcurra de Drago 1975), Bolívia (Boury-Esnault e Volkmer-Ribeiro 1991). Na Venezuela, os trabalhos de Bonetto e Ezcurra de Drago (1973), ofereceram relevantes aportes ao conhecimento das esponjas coletadas no rio Orinoco, com primeira descrição das espécies Drulia conifera, Stratospongilla spinifera e Stratospongilla intermedia, estas duas últimas colocadas posteriormente no gênero Oncosclera por Volkmer-Ribeiro e Pauls (1980). Estudos mais amplos e recentes sobre as coleções de esponjas de ambientes de águas continentais venezuelanas foram executados por Volkmer-Ribeiro e Pauls (2000), que teceram considerações quanto à morfologia, habitat, distribuição e produziram chave taxonômica para as esponjas da bacia do rio Orinoco.

As pesquisas sobre a ecologia atual das espécies de esponjas de água doce, seu ambiente de distribuição, características morfológicas e o conhecimento da sistemática do grupo são imprescindíveis e podem auxiliar estudos paleoambientais. $\mathrm{O}$ estabelecimento de coleções com as descrições e representações dos conjuntos espiculares característicos de táxons de esponjas modernas, torna-se referencial importante para a identificação taxonômica dessas espículas presentes em colunas sedimentares quaternárias, permitindo a determinação específica e validando o uso desse instrumento como recurso (dado proxy) para o entendimento e reconstituição dos eventos e processos que incidem nas mudanças ambientais. 


\section{Significado paleoambiental das espículas de esponjas}

As espículas de esponjas constituem uma ferramenta auxiliar eficaz em reconstruções paleoambientais e paleolimnológicas, dado as suas características intrínsecas para a deposição e acúmulo junto a sedimentos, principalmente do Quaternário. Isto se deve a composição silicosa do esqueleto de esponjas de água doce, fator que confere excepcional resistência a esses elementos frente ao processo de decomposição.

O emprego das espículas de esponjas como indicador proxy, teve início em meados da década de 1960, quando Racek (1966) proveu a primeira tentativa de utilização das espículas de poríferos continentais como ferramenta diagnóstica de mudanças paleoambientais. Destarte, estudando sedimentos de laguna da Guatemala, o autor apresentou ilustração dos conjuntos espiculares observados, sem, contudo, proceder à identificação das espécies. A escassez de estudos da fauna atual de esponjas continentais, somado a taxonomia confusa e inexistência de dados ecológicos para a época, emerge como uma das prováveis causas para o insucesso na identificação das espículas preservadas no registro sedimentar.

Não obstante, Harrison et al. (1979) analisaram sedimentos oriundos do Lago Okeechobee, na Florida, conseguindo chegar a uma identificação específica das espículas ocorrentes, com a determinação de Ephydatia fluviatilis Linnaeus, 1758, Spongilla alba Carter, 1849 e Trochospongilla leidyi Bowerbank, 1863.

A datação por radiocarbono permitiu estimar uma idade entre 4.000 e 3.000 anos AP, para os sedimentos estudados. Os autores constataram evidências de eutrofização do lago, valendo-se de estudos disponíveis sobre a ecologia atual das espécies de esponjas continentais para discutir e interpretar os sedimentos pretéritos. Posteriormente, Hall e Herrmann (1980) realizaram estudo paleolimnológico com três espécies de esponjas de água doce, com base em espículas recuperadas de sedimentos obtidos de um lago montanhoso situado no Colorado, Estados Unidos. Os sedimentos datados por ${ }^{14} \mathrm{C}$ revelaram idade igual a $6.680 \pm 400$ anos AP. Os autores também apresentaram discussão sobre a ecologia atual das esponjas identificadas, proporcionando uma caracterização precisa das condições ambientais pretéritas.

Em trabalhos congêneres, Harrison (1988), efetuou pesquisa abordando a utilização de esponjas de água doce em estudos paleolimnológicos, com enfoque para o hemisfério norte, demonstrando a validade do uso de espículas de esponjas continentais como ferramenta analítica em estudos dessa natureza.

No Brasil, os estudos envolvendo a utilização de espículas de esponjas continentais como proxy na interpretação paleoambiental foram produzidos inicialmente na Amazônia - Serra dos Carajás. Salienta-se o trabalho de Martin et al. (1992), que discutiram a respeito de algumas alterações climáticas registradas na América do Sul no intervalo de 7.000 anos AP., relacionadas provavelmente às condições do El Niño. Para tanto, os autores analisaram sedimentos de um perfil amostrado na Serra dos Carajás, no Estado do Pará, contemplando a variação de pólen e espículas de esponjas continentais, com a identificação da espécie Corvomeyenia thumi Traxler, 1895, que segundo observações apuradas pelos autores, trata-se de uma esponja de água doce típica de ambiente lacustre com lâmina d'água rasa, adaptada às secas episódicas, portanto, um importante bioindicador dessas condições ambientais.

Em trabalho subsequente, Sifeddine et al. (1994) coletaram dois perfis de sedimentos em dois lagos localizados na Serra Sul dos Carajás (Amazônia Oriental), constatando variações no regime hidrológico nos últimos 30.000 anos AP. Os resultados das análises do conteúdo de carvão, espículas de esponjas, com a presença de gemoscleras de C. thumi, aliado aos dados palinológicos, evidenciaram sequências interrompidas pela ocorrência de paleoincêndios, convergindo para períodos sucessivos de seca, com coluna de água reduzida. Cabe a ressalva que Volkmer-Ribeiro e Turcq (1996), estudando os mesmos perfis de sedimentos provenientes da Serra dos Carajás, já descritos e abordados por Sifeddine et al. (1994), processaram o exame pormenorizado das espículas da espécie C. thumi em Microscópio Eletrônico de Varredura (MEV). As avaliações mostraram que períodos extremamente curtos de imersão causaram uma série gradual de formações incompletas de espículas facilmente observadas ao MEV, sendo assim, sujeitas a correlação com períodos curtos e longos de imersão ou com disponibilidade de águas/chuvas para o sistema. Portanto, quanto ao grau de desenvolvimento das espículas analisadas, foi possível concluir uma sequência de períodos secos e úmidos.

Do mesmo modo, Cordeiro et al. (1997) elucidaram as mudanças ambientais na Região da Serra dos Carajás (Pará, Brasil) durante o Holoceno, a partir de um testemunho sedimentar lacustre $(68,5$ 
cm) coletado em um lago situado em uma depressão, sobre um platô laterítico na Serra Norte da área de estudo e datado em $6.803 \pm 50$ anos AP. Na pesquisa também foram identificadas espículas de C. thumi, que juntamente às análises dos conteúdos de matéria orgânica e carvão, bem como a presença de colônias de Botryococcus braunii (Chlorococcales), permitiram a interpretação da existência de duas fases distintas para a região, sendo uma em torno de 6.800 a 4.000 anos AP. e outra mais recente, de 4.000 anos AP. até o presente. A quantidade de espículas da esponja continental C. thumi, associado à ocorrência de colônias da alga $B$. braunii, atestaram que o lago já fora mais raso devido a episódios de seca no Holoceno.

Turcq et al. (1998) atentando-se para o estudo de um novo perfil de sedimentos lacustres coletado na Serra Sul dos Carajás, no Estado do Pará, Brasil, reportaram-se aos eventos desencadeados nos últimos 7.000 anos AP. e indicaram as mesmas considerações ambientais já apresentadas na região durante esse intervalo que abrange o Holoceno. Para tanto, ressalta-se que a pesquisa adotou a palinologia, contemplando, igualmente, a análise da concentração de sílica biogênica de espículas da espécie C. thumi, como referenciais instrumentais para a interpretação da dinâmica ambiental regional pretérita. Nesse sentido, ao descrever as variações ocorridas na Floresta Tropical Amazônica, os autores elencaram condições climáticas propícias para o desenvolvimento de florestas, no entanto, ponderando que essas eram eventualmente acometidas por sucessivos eventos de incêndios, marcados por episódios de clima seco.

Cabe destaque as inferências acerca dos paleoambientes e paleoclimas quaternários na região amazônica, mais precisamente na Serra dos Carajás, embora auxiliada por diferentes proxies, teve substancial contribuição de bioindicadores fósseis de sílica biogênica, com a identificação de espículas de uma única espécie de esponja, isto é, de C. thumi, que nesse caso, se configurou como uma ótima indicadora paleoambiental.

Todavia, estudos paleoambientais, com base em espículas de esponjas continentais, também foram executados por Cândido et al. (2000), ao observarem espículas presentes em sedimentos do Lago Caracaranã, localizado no Estado de Roraima, extremo norte do Brasil. Os dados evidenciaram a ocorrência pretérita de esponjas características de lagoas do bioma Cerrado: Metania spinata Carter, 1881; Radiospongilla amazonensis Volkmer-Ribeiro e Maciel, 1983; Trochospongilla variabilis Bonetto e Ezcurra de Drago, 1973 e Dosilia pydanieli Volkmer-
-Ribeiro, 1992, sendo essa última a única espécie atualmente ocorrente no lago. Os constituintes espiculares fósseis em comparação com o material atual de $D$. pydanieli confirmaram a identificação específica. Entretanto, os autores apontaram e ilustraram modificações das microscleras dessa espécie recuperadas do testemunho analisado $(190 \mathrm{~cm}$ de profundidade), interpretando essas variações como uma possível resposta ou adaptação às mudanças paleoambientais vigentes durante o Holoceno.

Volkmer-Ribeiro et al. (2001a) citaram exemplos de três casos já publicados de utilização de espículas de esponjas de água doce em estudos de reconstruções paleoambientais na América do Sul, compreendendo depósitos lacustres quaternários dispostos na Serra dos Carajás, no Pará, Brasil (Sifeddine et al. 1994, Cordeiro et al. 1997) e em Roraima, no extremo norte do país (Cândido et al. 2000). Tais estudos reforçam a importância desses compostos de sílica biogênica como parâmetro paleoindicador, uma vez que, associado a outros proxy (análise multiproxy), permitem a compreensão da evolução da paisagem e as mudanças ambientais ocorridas em uma região ao longo de um determinado espaço de tempo geológico.

Volkmer-Ribeiro et al. (2001b) realizaram a prospecção de esponjas vivas e análise do conteúdo de espículas de esponjas continentais dispersas em testemunhos sedimentares no lago do Caçô, na região nordeste do Estado do Maranhão, notando ainda a presença de frústulas de diatomáceas. Os resultados obtidos indicaram tanto a ocorrência de exemplar vivo de $M$. spinata, quanto o registro de espículas dessa espécie nos sedimentos amostrados. Os autores concluíram que as fases de disponibilidade hídrica do ambiente propiciavam condições favoráveis para a colonização da fauna de esponjas, sem a necessidade de produção de gêmulas. Já os estratos com ausência desses bioindicadores, sugeriam interrupção abrupta e episódica de alimentação hídrica do sistema, porém nunca suficientes para determinarem a formação de um ambiente tipicamente lêntico, sujeito a reduções estacionais de água, tendendo assim, mais para um ambiente semi-lótico semelhante ao atual.

Para a região mais continental, Parolin et al. (2003) ofereceram a caracterização paleoambiental de sedimentos de três lagoas (Samambaia, Linda e Dos 32) na região de Taquaruçu, no Mato Grosso do Sul, tendo como foco a avaliação de espículas silicosas de esponjas de água doce. Os resultados apontaram que essas lagoas, embora próximas, apre- 
sentaram gêneses distintas, corroborando a predominância de um clima mais seco na região antes do Holoceno e durante o Holoceno Médio.

No mesmo ano, convém mencionar que Pisera e Sáez (2003) publicaram o primeiro registro fóssil de esponjas de água doce do gênero Ephydatia no Hemisfério Sul. Os restos fósseis foram encontrados em sedimentos lacustres de diatomitos da Formação Quillagua, na região de Atacama, porção central dos Andes, no norte do Chile, com posição no Mioceno Tardio. Porquanto, no curso de suas investigações, os autores definiram uma nova espécie de esponja, correspondente a Ephydatia chileana, que apresentou um padrão morfológico de espículas similar aos descritos para a espécie atual de E. fluviatilis e se mostrou uma boa indicadora de condições paleoambientais.

Posteriormente, Volkmer-Ribeiro et al. (2004) traçaram um panorama da evolução costeira de sete lagoas que integram o Sistema Hidrológico do TAIM, no Rio Grande do Sul, Brasil, com respaldo da análise do conteúdo espicular presente nos sedimentos recolhidos dessas lagoas. Nesse sentido, identificaram e ilustraram espículas da espécie Ephydatia facunda Weltner, 1895, típica de lagoas de ambientes costeiros, avaliando a ocorrência quantitativa das espículas que revestem as gêmulas (gemoscleras). Verificaram a maior produção de esponjas no ambiente enriquecido de matéria orgânica, evoluindo para o sistema de banhado.

Parolin et al. (2005) detalharam as mudanças paleoambientais na região de Taquarussu, no Mato Grosso do Sul, tendo em vista sedimentos de dois testemunhos de sondagem recuperados da lagoa Samambaia. Estudou-se a variação da composição das assembleias de esponjas através de espículas contidas nos sedimentos, bem como se observaram as sequências sedimentares com predomínio de espículas de espécies de esponjas indicadoras de condições paleoambientais locais, as quais os autores cunharam o termo espongofácies. Os dados obtidos descreveram significativas alterações ambientais e hidrológicas na região, marcada por fases secas, lacustres e fluviais desde o final do Pleistoceno e durante o Holoceno, com indícios da existência de paleodrenagens na área. Mais uma vez se demonstrou a confiabilidade da utilização das espículas de esponjas em trabalhos de interpretações paleoambientais, pois os resultados apresentados corroboram levantamentos paleoclimáticos já descritos para a região.

Em 2007, Volkmer-Ribeiro et al. realizaram o primeiro estudo de reconstituição paleoambiental com datação absoluta em área costeira da América do Sul, utilizando espículas de esponjas de água doce. Foram estudados e caracterizados sedimentos da Formação do rio Luján, na Província de Buenos Aires, Argentina, datados pelo método do Carbono 14, revelando idades entre o final do Pleistoceno e início do Holoceno. A pesquisa mostrou não ser possível a identificação e ilustração de espículas da espécie E. facunda, assinalando um período de sedimentação lacustre em 11.060 a 10.420 anos AP, cuja espécie de esponja sugere o estabelecimento de um ambiente costeiro lagunar, confirmado ainda pela ocorrência da diatomácea Hyalodiscus subtilis (Bailey).

Da mesma forma, Parolin et al. (2007) demonstraram as mudanças paleoambientais no Alto rio Paraná durante o Holoceno, com base na análise de espículas de esponjas de água doce em amostras de sedimentos turfosos, obtidas em duas perfurações na região de Taquarussu, no Estado do Mato Grosso do Sul, Brasil. Datações por ${ }^{14} \mathrm{C}$ indicaram idades que oscilaram entre $11.570 \pm 80$ anos AP $(240 \mathrm{~cm}$ de profundidade) e $4.010 \pm 80$ anos AP $(29-35 \mathrm{~cm})$.

No estudo foram detectadas espículas de Heterorotula fistula Volkmer-Ribeiro e Motta, 1995, $R$. amazonensis, ambas as espécies típicas de ambientes lênticos, bem como de Corvospongilla seckti Bonetto e Ezcurra de Drago, 1966 e Trochospongilla repens Hinde, 1888, essas duas últimas com comunidades características de ambientes lóticos. Verificou-se a alternância na ocorrência de espículas dessas espécies ao longo da coluna sedimentar, com inferências de pulsos de inundação na planície do rio Esperança, que acredita-se serem responsáveis pela formação da turfa. Os resultados apresentados reiteram os estudos palinológicos já produzidos para a região e constitui o primeiro registro fóssil datado para $H$. fistula e T. repens.

Parolin et al. (2008) deram continuidade as pesquisas empreendidas na região de Taquarussu, no Mato Grosso do Sul, levando a efeito discussões previamente abordadas em estudos precedentes. No presente trabalho, sedimentos recuperados da Lagoa Samambaia foram datados pelo método de termoluminescência. A identificação taxonômica das espículas detectadas no material sedimentar mostrou a ocorrência pretérita das esponjas $D$. pydanieli, M. spinata, $R$. amazonensis, Corvospongilla sp. e Oncosclera sp., sugerindo uma alternância de fases lóticas e lênticas. Os autores introduziram o termo espongofácies para descrever as sequências sedimentares nas quais espículas de espécies de esponjas continentais predominam e indicam condições paleoambientais específicas, reassegurando 
a sua viabilidade como um dado proxy.

As contribuições sobre o uso de espículas de esponjas de água doce como indicadores de paleoambientes podem ser constatadas, igualmente, no trabalho de Almeida et al. (2009). O estudo teve como objetivo caracterizar depósitos de espongilito de lagoas situadas na região de João Pinheiro, no noroeste do Estado de Minas Gerais, Brasil, identificando espículas de esponjas formadoras de espongofacies e que integram espécies com ocorrência atual no Bioma Cerrado. Os resultados assinalam uma variação ambiental na época da formação dos depósitos analisados, alternando períodos de clima mais úmido e frio e de clima mais seco com chuvas torrenciais no espaço de tempo que compreende o Pleistoceno Superior e Holoceno.

Machado (2009) informou a ocorrência de espículas de esponjas continentais e camadas de espongilitos intercaladas por diatomitos (depósitos com predominância de frústulas de diatomáceas) em estudo operado no Afloramento Paleolago Cemitério, que compreende um depósito lacustre localizado no município de Catalão, sudeste do Estado de Goiás, Brasil. As análises taxonômicas das espículas no depósito confirmaram a existência de uma antiga comunidade de esponjas, tanto de ambiente lêntico quanto lótico, evidenciando a contribuição de um sistema lótico no início da formação do Paleolago, marcado por um aporte significativo de águas com fluxo devido ao padrão das espículas detectadas. Por ora, com base em suas investigações, a autora propôs dois paleoambientes diferenciados para o Paleolago Cemitério, denotando a ocorrência inédita de diatomitos e espongilitos em um mesmo depósito, além de efetuar o primeiro registro de espículas da espécie Corvoheteromeyenia australis Bonetto e Ezcurra de Drago, 1966 em comunidade formadora de espongilitos. Ressalta-se que a pesquisa registrou no depósito estudado espículas de esponjas que são características de espécies consideradas indicadoras de lagoas típicas de Cerrado, sugerindo a existência desse Bioma, na região central do Brasil, já no final do Pleistoceno e apontando para a presença de ambiente pretérito similar, na região sudeste de Goiás.

Estudos mais recentes dedicados ao reconhecimento de mudanças ambientais no Quaternário foram realizados por Rezende (2010), que baseando-se na análise micropaleontológica de espículas de esponjas recuperadas de testemunhos de sedimentos lacustres, obtidos da Lagoa Fazenda (município de São Tomé) e Lagoa Seca (município de Japurá), delineou a conjuntura paleoambiental na região noroeste do Estado do Paraná. Em pesquisa comparativa, vale notar que as espículas identificadas na área selecionada por Rezende (2010), revelaram afinidades taxonômicas com os materiais descritos por Parolin (2006) para as lagoas da região de Taquarussu, no sudeste do Mato Grosso do Sul, mostrando que muitas das espécies de esponjas registradas, através de espículas contidas nos sedimentos, são comuns a ambas as regiões e podem traduzir ambientes sujeitos à secas estacionais. As interpretações apresentadas no referido trabalho confirmam um paleoclima mais seco no final do Pleistoceno e a ocorrência de diversas oscilações climáticas no Holoceno, com fases mais secas durante o Holoceno Inferior e Médio, registrando-se um aumento da umidade desde o Holoceno Superior aos dias atuais.

Em sua tese de doutoramento, Kuerten (2010) realizou a compartimentação geomorfológica e a reconstituição das mudanças paleoambientais e paleo-hidrológicas do Pantanal do Nabileque, assim conhecido para se referir a uma das sub-regiões que integram o Pantanal Mato-Grossense. A análise circunstanciada dos compartimentos da área possibilitou a sua caracterização como um sistema de megaleque fluvial, construído pelo rio Paraguai, no qual foram reconhecidas três principais unidades geomorfológicas, assim definidas: a) planície aluvial degradada; b) cinturão de meandros abandonados e c) cinturão de meandros atual. Ao utilizar espículas como indicadores proxy, o autor concluiu que o cinturão de meandros abandonado do megaleque do Nabileque, experimentou mudanças de ambiente fluvial mais úmido para ambiente lêntico mais seco, inferindo uma mudança de curso do rio Paraguai entre 6.700 e $3.900 \mathrm{Ka}$ AP.

Guerreiro (2011) dissertou sobre a evolução geomorfológica e paleoambiental nos terraços da margem esquerda do alto rio Paraná, no noroeste do Estado do Paraná, próximo à cidade de Querência do Norte. Digno de nota, as evidências de espículas em sedimentos lacustres, que segundo interpretações efetuadas pelo autor, descartam a contribuição de ambientes lóticos na gênese e evolução das lagoas que ocorrem na região.

Da mesma forma, a contribuição de Silva et al. (2012), apresentou o primeiro estudo no Centro-Sul do Brasil sobre caracterização de níveis marinhos com base em espículas e datações absolutas. Os autores detalharam as mudanças paleoambientais na região do baixo curso do rio Ribeira de Iguape (Iguape/SP), no sudeste do Brasil, onde foram detectadas espículas de esponjas de água doce e 
marinhas, indicando fases com grandes oscilações do nível do mar entre 6.240 e 4.500 anos AP, e fases com predomínio de fluxos de água doce entre 4.500 e 2.920 anos AP. Os autores também postularam uma possível mudança do canal do rio Ribeira de Iguape, para oeste do local amostrado, durante o Holoceno.

Recentemente, Guerreiro et al. (2013) relataram as condições paleoambientais em cinco testemunhos recuperados de lagoas e leque aluvial da margem esquerda do alto rio Paraná, no noroeste do Estado do Paraná, a partir da análise do conteúdo de espículas silicosas de esponjas de água doce. A determinação específica das esponjas possibilitou reconstituir condições ambientais mais secas que as atuais no alto rio Paraná do Pleistoceno Tardio até o início do Holoceno, registrando a transição de climas secos pleistocênicos para climas úmidos no Holoceno, com formação de leque aluvial, datado em 7.540 anos AP. Os resultados alcançados nesse estudo estão de acordo com outros trabalhos que sugerem semelhantes condições climáticas para esse período do Quaternário, as quais já foram retratadas em estudos antecedentes desenvolvidos pelos mesmos autores (Guerreiro et al. 2010, Guerreiro 2011).

A figura 1 mostra a distribuição das ocorrências de espículas de esponjas de água doce e sua aplicação como instrumento de interpretação paleoambiental no Brasil.

\section{Conclusões}

O trabalho realizou uma síntese acerca das ocorrências de esponjas de água doce na América do Sul, com enfoque para o Brasil, e sua aplicação como ferramenta de interpretação paleoambiental, por meio das espículas silicosas preservadas em depósitos sedimentares de idade quaternária.

Do que foi levantado conclui-se que o conhecimento é incipiente, incompleto, e somente a partir da década de 1960, houve o incremento dos estudos envolvendo os levantamentos e descrições da espongiofauna de ambientes de água doce no Brasil, sendo que, nesse período, nota-se a contribuição referente aos estudos taxonômicos, com a revisão e criação de gêneros, inventários e descrições de novas espécies. Estudos abrangentes foram executados, principalmente, na região amazônica e no Estado do Rio Grande do Sul.

As publicações que tratam do emprego das espículas de esponjas de água doce como ferramenta para reconstrução paleoambiental, indicam que as abordagens com essa temática no Brasil, iniciaram na Amazônia - Serra dos Carajás, no decurso da década de 1990 e se encontram relativamente desenvolvidas no país, principalmente para a região Centro-Sul e Norte, onde há maior número de trabalhos publicados. Por fim, o trabalho evidencia o estágio atual dos estudos sobre a espongiofauna sul-americana, destacando as persbectivas e a necessidade da realiza-

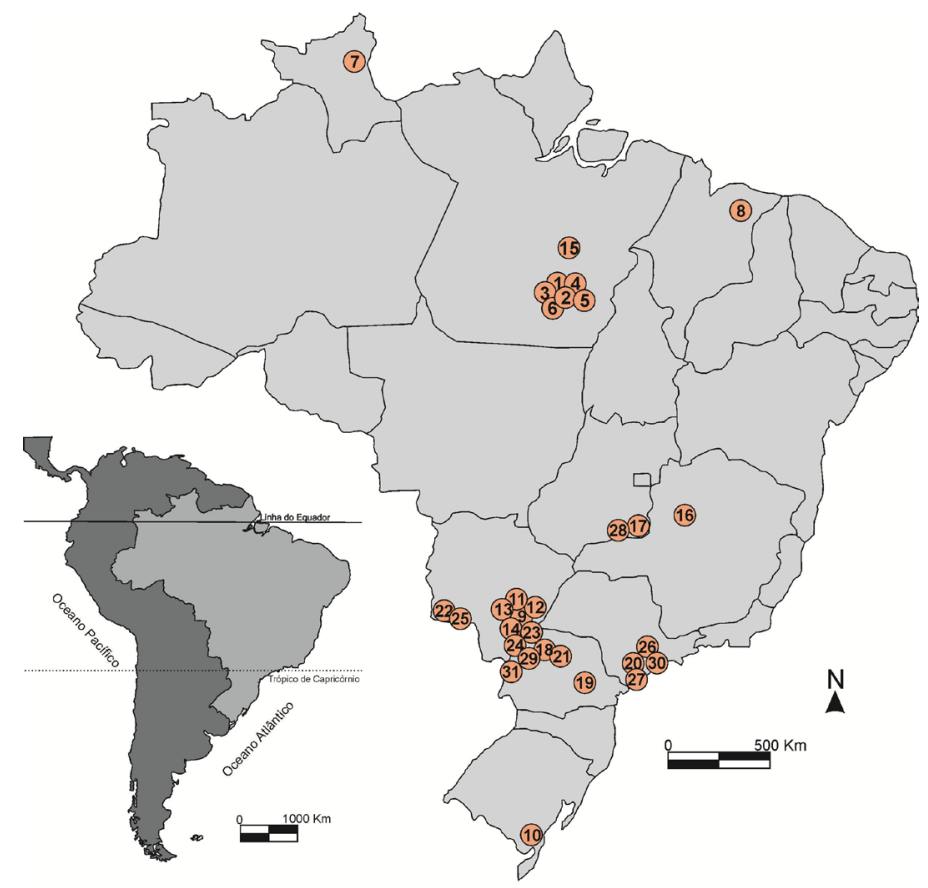

Figura 1. Distribuição das ocorrências de espículas de esponjas de água doce utilizadas como instrumentos de reconstrução paleoambiental no Brasil. Fonte: Base cartográfica do IBGE (2010) 
ção de trabalhos mais abrangentes e intensivos, para ampliar o conhecimento dessa fauna nas áreas que carecem de um esforço amostral e de levantamentos mais pormenorizados para a detecção de esponjas, além da importância da elaboração de uma coleção de referência com as descrições das espículas presentes em táxons de esponjas atuais, como subsídio aos estudos paleoambientais.

\section{Agradecimentos}

Os autores agradecem ao Conselho Nacional de Desenvolvimento Científico e Tecnológico (CNPq processo 471385/2012-3). A primeira autora agradece à CAPES (Coordenação de Aperfeiçoamento de Pessoal de Nível Superior) pela concessão da bolsa de mestrado e o segundo e terceiro autores agradecem a bolsa de produtividade da Fundação Araucária.

\section{Referências}

Almeida A.C.S., Volkmer-Ribeiro C., Varajão A.F.D.C., Gomes N.S., Varajão C.A.C. 2009. Espículas de esponjas continentais nos sedimentos cenozóicos do noroeste de Minas Gerais, como indicadores paleoambientais. Rev. Bras. Paleont., 12(2):123-138.

Batista T.C.A., Volkmer-Ribeiro C. 2002. Comunidades de esponjas do curso superior dos rios Paraná (Goiás) e Paraguai (Mato Grosso), Brasil, com redescrição de Oncosclera schubarti (Bonetto \& Ezcurra de Drago). Rev. Bras. Zool., 19(1):123-136.

Batista T. C. A., Volkmer-Ribeiro C., Darwich A., Alves L. F. 2003. Freshwater sponges as indicators of floodplain lake environments and of river rocky bottoms in Central Amazonia. Amazoniana, Kiel, 17(3/4): 525-549.

Bonetto A. A., Ezcurra de Drago I. 1973. Aportes al conocimiento de las esponjas del Orinoco. Physis, 32(84): 19-27.

Bonetto A. A., Ezcurra de Drago I. 1968. El gênero Spongilla Lamarck en el rio Uruguay. Physis, Buenos Aires, 27(75): 429-436.

Bonetto A. A., Ezcurra de Drago I. 1969. Notas sistematicas sobre el genero Uruguaya Carter (Porifera, Spongillidae). Physis, Buenos Aires, 28(77): 351-357.

Bonetto A. A., Ezcurra de Drago I. 1966. Nuevos aportes al conocimiento de las esponjas argentinas. Physis, Buenos Aires, 26(71): 129-140.

Boury-Esnault N., Volkmer-Ribeiro C. 1991. Las esponjas. In: Dejoux C., Iltis A. eds. 1991. El lago Titicaca, sinteses del conocimiento limnológico actual. La Paz: O.R.S.T.O.M. e Instituto de Historia Social Boliviana. p. 305-310.

Bowerbank J. S. 1863. A monograph of the Spongilli- dae. Proc. Zool. Soc. London, p. 440-472.

Cândido J. L., Volkmer-Ribeiro C., Simões Filho F. L., Turcq B. J., Desjardins T., Chauvel A. 2000. Microsclere variations of Dosilia pydanieli (Porifera, Spongillidae) in Caracaranã lake (Roraima - Brazil): Palaeoenvironmental implication. Biociências, Porto Alegre, 8(2): 77-92.

Carvalho J. P. 1942. Ocorrência de Ephydatia crateriformis (Potts) na América do Sul. Bol. Fac. Filos., Cienc. e Letras Univ. São Paulo, 6: 267-269.

Cordeiro R. C., Turcq B., Suguio K., Volkmer-Ribeiro C., Silva A. O., Sifeddine A., Martin L. 1997. Holocene environmental changes in Carajás Region (Pará, Brazil) recorded by lacustrine deposits. Verh Int. Verein Limnol., Stuttgart, 26: 814-817.

Custódio M. R., Hajdu E. 2011. Checklist de Porifera do Estado de São Paulo, Brasil. Biota Neotrop., Supl. 1, 11: 427-444.

De Rosa-Barbosa R. 1979. Redescrição do material tipo de Ephydatiafacunda Weltner, 1895 (Porifera-Spongillidae). Iheringia Ser. Zool., Porto Alegre, 54: 27-34.

Ezcurra de Drago I., Bonetto A. A. 1969. Algunas caracteristicas del bentos en los saltos del rio Uruguay, con especial referencia a la ecologia de los poriferos. Physis, Buenos Aires, 28(77): 359-369.

Ezcurra de Drago I. 1975. Freshwater sponges of Suriname. Stud. fauna Suriname and other Guyanas, 15(57): 175-183.

Ezcurra de Drago I. 1974. La presencia de Spongilla (Eunapius) fragilis Leidy en Chile (Porifera, Spongillidae). Physis, 33(87): 249-252.

Ezcurra de Drago I. 1977. Porifera. In: Hulbert S. H. ed. 1977. Aquatic Biota of Southern South America. San Diego State University, San Diego, California. p. 57-61.

Ezcurra de Drago I. 1978. Una nueva especie de Stratospongilla Annandale, 1909, para Sudamerica (Porifera, Spongillidae). Neotrop., 24(72): 105-110.

Ezcurra de Drago I. 1979. Un nuevo genero sudamericano de esponjas: Corvoheteromeyenia gen. nov. (Porifera Spongillidae). Neotrop., 25(74): 109-118.

Frost T. M. 1991. Porifera. In: Thorp J. H., Covich A. P. eds. 1991. Ecology and Classification of North American Freshwater Invertebrates. New York: Academic Press. p. 95-124.

Guerreiro R. L. 2011. Evolução geomorfológica e paleoambiental dos terraços da margem esquerda do alto rio Paraná. Rio Claro - SP: Inst. Geoc. e Ciências Exatas. Univ. Est. Paulista. 67p. (Dissert. Mestrado).

Guerreiro R. L., Parolin M., Assine M. L., Stevaux J. C. 2010a. Dados proxy indicam melhoria climática na região de Querência do Norte a 7.540 anos AP. In: II Simpósio Paranaense de Estudos Climáticos e XIX Semana de Geografia. Anais, Maringá, p. 320-333.

Guerreiro R. L., Parolin M., Assine M. L., Stevaux J. C. 2010b. Optimum climaticum a 7.540 anos AP na re- 
gião de Querência do Norte, Noroeste do Paraná. In: IV Encontro dos Programas de Pós-Graduação em Geociências. Rio Claro - SP.

Guerreiro R. L., Stevaux J. C., Parolin M., Assine M. L. 2013. Late Pleistocene and Holocene paleoenvironments in ponds and alluvial sediments of upper Paraná river, Brazil. Rev. Bras. Paleont., 16(1): 39-46.

Hall B. V., Herrmann S. J. 1980. Paleolimnology of three species of freshwater sponges (Porifera: Spongillidae) from a sediment core of a Colorado semidrainage mountain lake. Trans. Am. Microsc. Soc., Lawrence, 99(1): 93-100.

Harrison F. W., Gleason P. J., Stone P. A. 1979. Paleolimnology of lake Okeechobee, Florida: an analysis utilizing spicular components of freshwater sponges (Porifera: Spongillidae). Not. Nat., Philadelphia, 454: 1-6.

Harrison F. W. 1988. Utilization of freshwater sponges in paleolimnological studies. Palaeogeogr., Palaeoclimatol., Palaeoecol., Amsterdam, 62: 387-397.

Kilian E. F., Wintermann-Kilian G. 1976. Die Spongilliden Südamerikas: derzeitiger Stand der Kenntnis ihrer Verbreitung. In: Descimon H. ed. 1976. Biogeographie et evolution en Amerique tropicale. Publications du Laboratoire de Zoologie de l'École Normale Superieure, Paris, 9: 75-97.

Kuerten S. 2010. Evolução geomorfológica e mudanças ambientais no megaleque do Nabileque, Quaternário do Pantanal Mato-Grossense. Rio Claro - SP: Inst. Geoc. e Ciências Exatas, Univ. Est. Paulista. 96 p. (Tese Doutorado).

Kuerten S., Parolin M., Assine M. L. 2011. Espículas de esponjas continentais preservadas em sedimentos arenosos quaternários do Pantanal. In: XIII Congresso da Associação Brasileira de Estudos do Quaternário - ABEQUA. Anais, Búzios/RJ.

Lutz A., Machado A. 1915. Viagem pelo rio São Francisco e por alguns dos seus afluentes entre Pirapora e Juazeiro. Mem. Inst. Oswaldo Cruz, 7(1): 5-50.

Machado O. X. B. 1947. Contribution à l'étude de la faune du Brésil. Nouvelle espèce de spongiaire fluvial: Tubella mello-leitaoi O. Machado. Bull. Soc. Zool. France, 72(1): 133-135.

Machado V. S. 2009. Espongofauna do Paleolago Cemitério, Catalão, GO. Porto Alegre: Inst. Geoc. Univ. Fed. do Rio Grande do Sul. 118 p. (Dissert. Mestrado).

Machado V. S., Volkmer-Ribeiro C., Iannuzzi R. 2012. Inventary of the Sponge Fauna of the Cemitério Paleolake, Catalão, Goiás, Brazil. An. Acad. Bras. Cienc., 84(1): 17-34.

Marcotti T. C. B. 2012. Paleogeografia do Pleistoceno Tardio e Holoceno na região baixo curso do rio Ivaí - Icaraíma e Santa Mônica/PR. Maringá: Univ. Est. de Maringá, Centro de Ciências Humanas, Letras e Artes, Progr. Pós-Grad. Geografia. 62 p. (Dissert. Mestrado). Marcotti T. C. B., Parolin M., Santos M. L. 2011. Espículas de esponjas e fitólitos no Pleistoceno
Tardio indicam presença e abandono de canal fluvial - rio Ivaí Paraná. In: XIII Congr. da Assoc. Brasileira de Estudos do Quaternário ABEQUA. Anais, Búzios, RJ.

Martin L., Absy M. L., Fournier M., Mouguiart P., Sifeddine A., Volkmer-Ribeiro C. 1992. Some climatic alterations recorded in South America during the last 7000 years may be expounded by long-term El Niño like conditions. Paleo Enso Records, Lima, p. 187-192.

Moro R. S., Parolin M., Menezes H. R. 2009. Inferências paleoclimáticas do início do Holoceno com base em espículas de esponjas continentais Lagoa Dourada/PR. Paleont. em Destaque: Bol. Inf. Soc. Bras. Paleont., 24(62): 5-6.

Muricy G., Lopes D. A., Hajdu E., Carvalho M. de S., Moraes F. C., Klautau M., Menegola C., Pinheiro U. 2011. Catalogue of Brazilian Porifera. Rio de Janeiro: Museu Nacional. 300p.

Parolin M. 2006. Paleoambientes e paleoclimas no final do Pleistoceno e no Holoceno no Sudeste do Estado do Mato Grosso do Sul. Maringá: Progr. Pós-Grad. em Ecologia de Ambientes Aquáticos Continentais, Univ. Est. Maringá. 121p. (Tese Doutorado).

Parolin M., Volkmer-Ribeiro C, Stevaux J. C. 2003. Caracterização paleoambiental a partir de espículas silicosas de esponjas em sedimentos lagunares na região de Taquaruçu - MS. Paleo 2003 - Reunião Regional de Paleontologia. Paleont. em Destaque, Porto Alegre, 44: 18.

Parolin M., Volkmer-Ribeiro C., Stevaux J. C. 2005. Mudanças ambientais durante o Holoceno e final do Pleistoceno indicadas por espongofacies na região de Taquarussu/MS - Brasil. In: X Congr. ABEQUA. Anais.

Parolin, M., Volkmer-Ribeiro C., Stevaux J. C. 2007. Sponge spicules in peaty sediments as paleoenvironmental indicators of the Holocene in the upper Paraná river, Brazil. Rev. Bras. Paleont., Porto Alegre, 10(1): 17-26.

Parolin M., Volkmer-Ribeiro C., Stevaux J. C. 2008. Use of spongofacies as a proxy for river-lake paleohydrology in Quaternary deposits of CentralWestern Brazil. Rev. Bras. Paleont., 11(3): 187-198.

Penney J. T., Racek A. A. 1968. Comprehensive revision of a worldwide collection of freshwater sponges (Porifera: Spongillidae). U.S. Nat. Mus. Bull., 272: 1-184.

Pinheiro U. S. 2007. Contribuições à taxonomia e biogeografia das esponjas de águas continentais brasileiras. Rio de Janeiro: Univ. Fed. Rio de Janeiro, Museu Nacional. 220p. (Tese Doutorado).

Pinheiro U. S., Hajdu E., Caballero M. E. 2003. Três novos registros de esponjas (Porifera, Demospongiae) para águas continentais do Estado de São Paulo. Bol. Mus. Nac, Nova Série, Zoologia, Rio de Janeiro, 498: 1-14. 
Pisera A., Sáez A. 2003. Paleoenvironmental significance of a new species of freshwater sponge from the Late Miocene Quillagua Formation (N Chile). J. South Am. Earth Sci., 15: 847-852.

Racek A. A. 1966. Spicular remains of freshwater sponges. Mem. Conn. Acad. Arts Sci., New Haven, 17: $78-23$

Rezende A. B. 2010. Espículas de esponja em sedimentos de lagoa como indicador paleoambiental no NW do Estado do Paraná. Guarulhos-SP: Univ. Guarulhos. 65p. (Dissert. Mestrado).

Rezende A. B., Fernandes R. S., Stevaux J. C., Parolin M. 2009. Paleoambientes da Lagoa Fazenda (São Tomé - PR) com base em espículas silicosas de esponjas continentais. Bol. Soc. Bras. Paleont., 62: 6.

Santos C. S. 2010. Análise de restos silicosos biogênicos como evidência das variações do Nível Relativo do Mar durante o Holoceno na Estação Ecológica Juréia-Itatins, São Paulo. Guarulhos: Univ. Guarulhos. 78p. (Dissert. Mestrado).

Santos C. S., Suguio K., Moraes F. C., Sallun A. E. M., Garcia M. J., De Oliveira P. E., Medeiros V. B., Sallun Filho W. 2011. Caracterização dos tipos de espículas de esponjas silicosas encontradas em sedimentos paleolacustres coletados na Estação Ecológica de Juréia-Itatins, São Paulo. Rev. UnG - Geociências, 10(1): 64-73.

Sifeddine A., Frohlich F., Fournier M., Martin L., Servant M., Soubiès F., Turcq B., Suguio K., Volkmer-Ribeiro C. 1994. La sedimentation lacustre indicateur de changements des paleoenvironments aucours des 300.000 derniere annees Carajás Amazonie, Brésil. C R Acad. Sci., Paris, 318(2): 1645-1652.

Sifeddine A., Martin L., Turcq B., Volkmer-Ribeiro C., Soubiès F., Cordeiro R. C., Suguio K. 2001. Variations of the Amazonian rainforest environment: a sedimentological record covering 30,000 years. Palaeogeogr., Palaeoclimatol., Palaeoecol., 168: 221-235.

Silva K. C., Parolin M., Bissa W. M. 2011. Espículas de esponjas em turfeira no baixo curso do rio Ribeira de Iguape (SP) indicam variações do nível relativo do mar durante o Holoceno Médio. In: XIII Congr. Assoc. Brasileira de Estudos do Quaternário ABEQUA. Anais, Búzios, RJ.

Silva K. C., Parolin M., Bissa W. M. 2012. Espículas de esponjas vs. variações do nível relativo do mar na região de Iguape, sudeste do Brasil. Rev. Bras. Paleont., 15(3): 319-326.

Tavares M. C. M. 1994. Comunidades de esponjas de substratos rochosos de rios amazônicos com redefinição e chave taxonômica para as espécies do gênero Drulia Gray (1867). (Porifera: Demospongiae). Porto Alegre: Pontifícia Universidade Católica do Rio Grande do Sul. 74p. (Dissert. Mestrado).

Turcq B., Sifeddine A., Martin L., Absy M. L., Soubies F., Suguio K., Volkmer-Ribeiro C. 1998. Amazo- nia Rainforest Fires: A Lacustrine Record of 7000 years. Ambio, 27(2): 139-142.

Van Soest R. W. M., Boury-Esnault N., Hooper J. N. A., Rützler K., de Voogd N. J., Alvarez de Glasby B., Hajdu E., Pisera A. B., Manconi R., Schoenberg C., Janussen D., Tabachnick K. R., Klautau M., Picton B., Kelly M., Vacelet J., Dohrmann M., Cristina Díaz M., Cárdenas P. (2014). World Porifera database. URL: < http://www.marinespecies.org/ porifera >. Acesso: 06.06.2014.

Volkmer-Ribeiro C. 1990. A new insight into the systematics, evolution, and taxonomy of freshwater sponges. In: Rützler K. ed. 1990. New Perspectives in Sponge Biology. Washington: Smithsonian Institution Press. 533p.

Volkmer-Ribeiro C., Cândido J. L., Turcq B. J., Sifeddine A., Cordeiro R. C., Filho F. L. S. 2001a. Silicious spicular remains of freshwater sponges and their contribution to paleoenvironmental reconstructions in South America. Actas V REQUI/I CQPLI, Lisboa. p. 411-413.

Volkmer-Ribeiro C., Sifeddine A., Albuquerque A. L. 2001b. Avaliação ambiental indicada por espículas silicosas de esponja nos sedimentos atuais e sub-fósseis do lago do Caçô, MA. In: VIII Congr. ABEQUA. Boletim de resumos, Imbé. p. 333-335.

Volkmer-Ribeiro C., De Rosa-Barbosa R. 1978. A new genus and species of Neotropical freshwater sponges. Iheringia, Ser. Zool., Porto Alegre, 52: 103-107.

Volkmer-Ribeiro C., De Rosa-Barbosa R. 1979. Neotropical freshwater sponges of the Family Potamolepidae Brien, 1967. In: Levi C., Boury-Esnault N. eds. 1979. Biologie des Spongiaires. Colloques Internationaux du C. N. R. S. 291. Paris: Centre National de la Recherche Scientifique, p. 503-511.

Volkmer-Ribeiro C. 1999. Esponjas. In: Joly C. A., Bicudo C. E. de M. eds. 1999. Biodiversidade do Estado de São Paulo: síntese do conhecimento ao final do século XX. São Paulo: FAPESP, 4. p. 1-9.

Volkmer-Ribeiro C. 1984. Evolutionary study of the genus Metania Gray, 1867 (Porifera: Spongillidae): II. Redescription of two Neotropical species. Amazoniana, Kiel, 8(4): 541-553.

Volkmer-Ribeiro C. 1986. Evolutionary study of the genus Metania Gray, 1867: III. Metaniidae, new Family. Amazoniana, 9(4): 493-509.

Volkmer-Ribeiro C., Ezcurra de Drago I., Parolin M. 2007. Spicules of the freshwater sponge Ephydatia facunda indicate lagoonal paleoenvironment at the pampas of Buenos Aires Province, Argentina. J. Coast. Res., 50: 449-452.

Volkmer-Ribeiro C., Guadagnin D. L., De Rosa-Barbosa R., Silva M. M., Drügg-Hahn S., Lopes-Pitoni V. L., Gastal H. A. de O., Barros M. P., Demaman L. V. 2004. A Polyethylenetherephthalate (PET) device for sampling freshwater benthic 
macroinvertebrates. Braz. J. Biol., 64(3): 531-541.

Volkmer-Ribeiro C., Hatanaka T. 1991. Composição específica e substrato da espongofauna (Porifera) no lago da Usina Hidroelétrica de Tucuruí, Pará, Brasil. Iheringia, Ser. Zool., Porto Alegre, 71: 177-178.

Volkmer-Ribeiro C., Machado V. de S. 2007. Freshwater sponges (Porifera, Demospongiae) indicators of some coastal habitats in South America: redescriptions and key to identification. Iheringia, Ser. Zool., Porto Alegre, 97(2): 157-167.

Volkmer-Ribeiro C., Maciel S. B. 1983. New freshwater sponges from Amazonian waters. Amazoniana, Kiel, 8(2): 255-264.

Volkmer-Ribeiro C., Marques D. M., De Rosa-Barbosa R., Machado V. S. 2004. Sponge spicules in sediments indicate evolution of coastal freshwater bodies. J. Coast. Res., 39: 469-472.

Volkmer-Ribeiro C. 1970. Oncosclera: a new genus of freshwater sponges (Porifera-Spongillidae) with redescription of two species. Amazoniana, 2(4): 435-442.

Volkmer-Ribeiro C., Parolin M. 2010. As esponjas. In: Parolin M., Volkmer-Ribeiro C., Leandrini J. A. eds. 2010. Abordagem ambiental interdisciplinar em bacias hidrográficas no Estado do Paraná. Campo Mourão: Editora da Fecilcam. p. 105-130.

Volkmer-Ribeiro C., Parolin M., Fürstenau-Oliveira K., Menezes E. R. 2010. Colonization of hydroelectric reservoirs in Brazil by freshwater sponges, with special attention on Itaipu. Interciência, Caracas, 35(5): 340-347.

Volkmer-Ribeiro C., Parolin M. 2005. Segundo registro de Sterrastrolepis brasiliensis Volkmer-Ribeiro
\& De Rosa-Barbosa (Demospongiae, Potamolepidae) com descrição do habitat e de assembleia, Bacia do Rio Paraná, Brasil. Rev. Bras. Zool., 22(4): 1003-1013.

Volkmer-Ribeiro C., Pauls S. M. 1980. Adiciones al conocimiento de la fauna de esponjas de agua dulce de Venezuela. VIII Congresso Latinoamericano de Zoologia. Livro de resumos: Merida. p. 44.

Volkmer-Ribeiro C., Pauls S. M. 2000. Esponjas de agua dulce (Porifera, Demospongiae)

de Venezuela. Acta Biol. Venez., 20 (1): 1-28.

Volkmer-Ribeiro C. Porifera. 1981. In: Hulbert S. H., Rodríguez G., Santos N. D. eds. 1981. Aquatic biota of tropical South America: being a compilation of taxonomic bibliographies for the fauna and flora of inland waters of the tropical portion of South America. San Diego: San Diego State University, Anartrophoda, 2. p. 86-95.

Volkmer-Ribeiro C. 2007. South American continental sponges: state of the art of the research. In: Custódio M. R., Lôbo-Hajdu G., Hajdu E., Muricy G. eds. 2007. Porifera Research: Biodiversity, Innovation and Sustainability. Rio de Janeiro: Museu Nacional. p. 117-121.

Volkmer-Ribeiro C. 1963. Spongilla jewelli n. sp. from freshwater sponge at Brazil. An. Acad. Bras. Cienc., 35(2): 271-274.

Volkmer-Ribeiro C., Turcq B. 1996. SEM analysis of silicious spicules of a freshwater sponge indicate paleoenvironmental changes. Acta Microscópica, Rio de Janeiro, 5: 186-187. Suplemento B.

Weltner W. 1895. Spongillidenstudien III. Katalog und Verbreitung der bekannten Süsswasserschwämme. Arch. für Naturgesch., 61(1): 114-144.

RESUM0: Este trabalho apresenta atualização bibliográfica da produção científica envolvendo a fauna de esponjas continentais na América do Sul, destacando os estudos efetuados no Brasil. Para isso foi realizado o levantamento das principais pesquisas que tratam do registro das ocorrências de esponjas de água doce, e daquelas sobre a utilização de suas espículas silicosas, preservadas em depósitos sedimentares, como dado proxy em estudos de reconstrução paleoambiental. Os estudos encontram-se relativamente mais desenvolvidos na região Centro-Sul e Norte do país. No entanto, fica evidente a necessidade de pesquisas mais abrangentes e intensivas na descrição de espécies atuais e de identificação em sequências sedimentares.

Palavras-chave: Esponjas de água doce, espículas silicosas, reconstrução paleoambiental. 